九州大学学術情報リポジトリ

Kyushu University Institutional Repository

\title{
Contribution of Rhododendron eriocarpum Nakai to the flower color variation in $R$. sataense Nakai
}

Miyajima, Ikuo

Laboratory of Horticultural Science, Faculty of Agriculture, Kyushu University

Miyahara, Kayo

Laboratory of Horticultural Science, Faculty of Agriculture, Kyushu University

Ureshino, Kenji

Laboratory of Horticultural Science, Faculty of Agriculture, Kyushu University

https://doi.org/10.5109/24286

出版情報：九州大学大学院農学研究院紀要. 43 (3/4)，pp.403-409，1999-02. Kyushu University バージョン：

権利関係 : 


\title{
Contribution of Rhododendron eriocarpum Nakai to the flower color variation in $R$. sataense Nakai
}

\author{
Ikuo Miyajima, Kayo Miyahara* and Kenji Ureshino \\ Laboratory of Horticultural Science, Faculty of Agriculture, \\ Kyushı University 46-01, Fukuoka 812-8581, Japan \\ (Received October 30,1998 and accepted Nowember 6, 1998)
}

\begin{abstract}
The origin of flower color variation in $R$. satuense was discussed by means of the comparison of some morphological characteristics of flowers and petal pigmentation in $R$. sataense with those of $R$. eriocarpum, $R$. kaempferi and their $F_{1}$ progenies. Flower color variations were very wide in $R$. sataense, whereas those in the two other wild species were extremely narrow. Although there were no $\mathrm{F}$; the individuals having vermilion or red flowers, the flower color variations of them were wider than those of $R$. eriocarpum.

The frequency of individuals having 5 stamens were highest in $R$. sataense and the number of stamens of $R$. kuempfer $i$ and $R$. eriocarpum were only $\tilde{5}$ and 10 , respectively. The number of stamens in the $F$, was different in the cross combinations.

Almost all individuals of $R$. eriocarpum contained a high ratio of methylated flavonols in their petals, whereas $R$. katmpferi contained few amount. However, there were two groups identified in the $F_{1}$ hybrids regarding to the constitutions of the flavonols in their petals; one group was formed with individuals containing high percentage of methylated flavonols and another containing low.

From these findings, it was possibly suggested that the appearance of the progenies with wide flower color variations, 5 stamens and containing few methylated flavonols in their petals such as $R$. sataense were able to be obtained from the crossing between $R$. eriocarpum and $R$. kaempferi.
\end{abstract}

\section{INTRODUCTION}

Rhododendron sataense Nakai distributes in the low altitude mountains and plateaus in southern Kyushu such as Mt. Taka-Toge, Mt. Sakurajima, Mt. Tsujigatake in Osumi peninsula and Mt. Kaimondake and surrounding of Ikeda lake in Satsuma peninsula. It is one of the wild evergreen azaleas and has a wide range of flower color variations (Abe, 1969). Based on its similarities in the morphological and pigmental characteristics to ornamental Kurume azalea, $R$. sataense has been regarded as one of the parents of Kurume azalea (Kunishige, 1978).

$R$. sataense has also been regarded as a local variety of $R$. kaempferi Planch. because of its similarity in petal size, blotch expression, and the growth habit of branches (Kunishige and Tamura, 1961). The morphological characters of the flowers of $R$. sataense are similar to those of $R$. kaempferi except for flower color variations.

Kunishige and Kobayashi (1980) reported that the wild evergreen azalea populations of which the flower colors range from vermilion through red, pink to purple are usually the progenies of natural crossings between the species having the anthocyanin of

\footnotetext{
* Present address: Oita Junior College, Oita 870-8658

Studies on the variations of characteristics in evergreen azaleas. V
} 
delphinidin series (purple flowers) and that of cyanidin series (red flowers). The extremely wide variation of flowcr colors in $R$. sataense, therefore, suggests that it is the result of interspecific crossing of wild evergreen azaleas.

In the previous report (Miyajima et al., 1997), we pointed out that the flower color variations of $R$. sataense do not seem to be derived from the natural crossing between $R$. kiusianum Makino and $R$. kaempferi from the constitutions of flavonol pigments in their petals.

In this report, we discuss the origin of flower color variation in $R$. sataense by means of the comparison with some morphological characteristics of flowers and petal pigmentation in $R$. sataense and $\mathrm{F}_{1}$ progenies of $R$. eriocarpum Nakai $\times R$. kaempferi.

\section{MATERIALS AND METHODS}

Plant materials used in this study are listed in Table 1 . The number of stamen were counted with five flowers in each species and $F_{1}$ progenies. Fully expanded petals were collected and the colors were identified according to the Royal Horticultural Society Colour Chart (RHSCC). Two ml of $2 \mathrm{~N}$ hydrochloric acid were added directly to the fresh petals and the flavonols in the petals were hydrolyzed for $90 \mathrm{~min}$ at $90^{\circ} \mathrm{C}$. After hydrolyzation, $2 \mathrm{ml}$ of distilled water were added and held on Sep-Pak cartridge $\left(\mathrm{C}_{18}\right.$, Millipore). The flavonol pigments on the cartridge were washed with distilled water to eliminate the water-soluble hydrophilic contaminants and eluted with $2 \mathrm{ml}$ of methanol. The methanol eluents were filtrated with membrane filter $(0.45 \mu \mathrm{m})$ and injected into high performance liquid chromatography (HPLC) developed with LC-6A pump (Shimadzu), $4.6 \mathrm{~mm}$ I.D. $\times 250 \mathrm{~mm}$ Cosmosil $5 \mathrm{C}_{1 \mathrm{~s}}-\mathrm{AR}$ column (Nakarai Tesque) and SPD-6AV detector (Shimadzu) set at $360 \mathrm{~nm}$. A flow rate of $1.0 \mathrm{ml} / \mathrm{min}$ was maintained and a mixture of acetonitrile- $0.1 \mathrm{M}$ acetic acid $(30: 70, \mathrm{v} / \mathrm{v})$ was employed as the eluant. The percentages of methylated flavonols were calculated as the ratios of 5-Omethylmyricetin and 5-0-methylquercetin in total flavonol aglycones.

Table 1. Number of individuals used in this investigalion.

\begin{tabular}{|c|c|c|}
\hline $\begin{array}{l}\text { Species and cross } \\
\text { combination }\end{array}$ & Collection site & $\begin{array}{l}\text { Number of } \\
\text { individuals }\end{array}$ \\
\hline R. eriocarpum & Tokara Islands, Kagoshima & 26 \\
\hline R. kaempferi & Sasaguri town, Fukuoka & 12 \\
\hline R. katmpferi & Tarumizu city, Kagoshima & 25 \\
\hline$R$. sataense & Mt. Taka-Toge, Kagoshima & 125 \\
\hline R. eriocarpum No. $1^{\prime} \times R$. kaempferi No. 1 & & 104 \\
\hline R. kaempferi No. $1 \times R$. eriocarpum No. 1 & & 93 \\
\hline R. kaempferi No. $2 \times R$. eriocarpure No. 2 & & 86 \\
\hline
\end{tabular}

${ }^{2}$ No. 1 , No. 2; individual numbers. 


\section{RESULTS AND DISCUSSION}

Figure 1 shows the results of HPLC separation and structures of the four flavonol aglycones found in the petals of evergreen azaleas. The order of the elution was 5-O-methylmyricetin, 5-0-methylquercetin (Azaleatin), myricetin and quercetin under our analytical conditions.

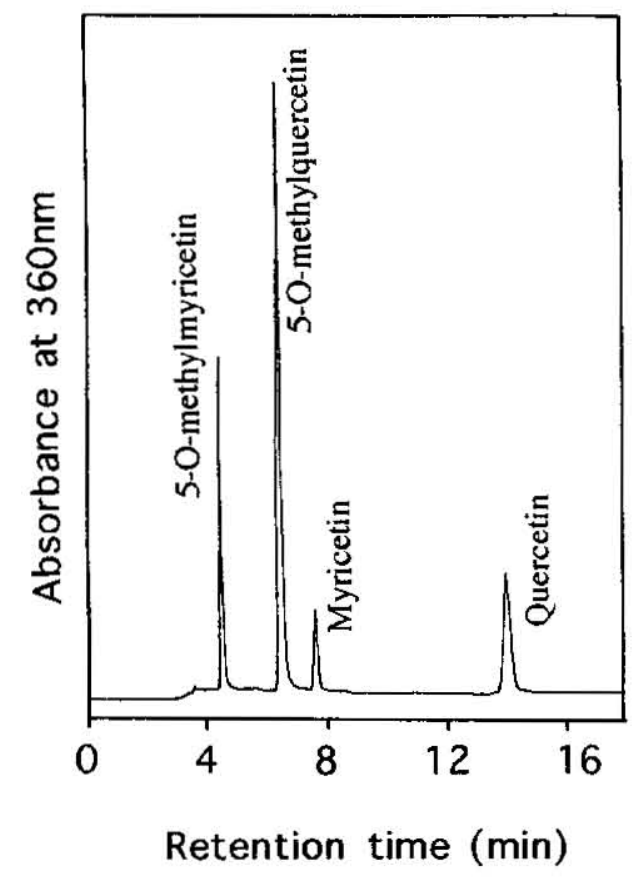<smiles>[R2]c1cc(-c2oc3cc(O)cc([R7])c3c(=O)c2O)cc(O)c1O</smiles>

5-O-methylmyricetin; $\mathrm{R}_{1}=\mathrm{OCH}_{3}, \mathrm{R}_{2}=\mathrm{OH}$ 5-O-methylquercetin (Azaleatin); $\mathrm{R}=\mathrm{OCH}_{3}, \mathrm{R}=\mathrm{H}$ Myricetin; $\mathrm{R}_{1}=\mathrm{OH}, \mathrm{R}_{2}=\mathrm{OH}$ Quercetin; $\mathrm{R}_{1}=\mathrm{OH}, \mathrm{R}_{i}=\mathrm{H}$

Fig. 1. HPLC profiles and structure of four flavonol aglycones in the petals of evergreen azaleas. The analytical conditions of HPLC are shown in the text.

Flower colors widely varied in $R$. sataerse, whereas they were extremely narrow in other two species; almost all $R$. eriocarpum and $R$. kaempferi flowers have pale purple (RHSCC No. $75<$ ) and vermilion (RHSCC No. $45>$ ) petals, respectively (Fig. 2).

Although there were no individuals that have vermilion or red flowers in $F_{1}$ progenies, the flower color variations of the both $\mathrm{F}_{1}$ progenies obtained from the crossings between R. kaempferi No. 1 (RHSCC No. 48) and $R$. eriocarpum. No. 1 (RHSCC No. 84), and between $R$. katmpferi No. 2 (RHSCC No. 51) and $R$. eriocarpum No. 2 (RHSCC No. 84) were wider than those of $R$. eriocarpum.

The frequency of individuals having 5 stamens were highest in $R$. sataense, and $R$. kaempferi and $R$. eriocarpum had only 5 and 10 stamens, respectively (Fig. 3). The number of stamens in the $F_{1}$ hybrids between $R$. eriocarpum and $R$. kaempferi were dependent in the cross combinations. The progenies that had 5 stamens were most 


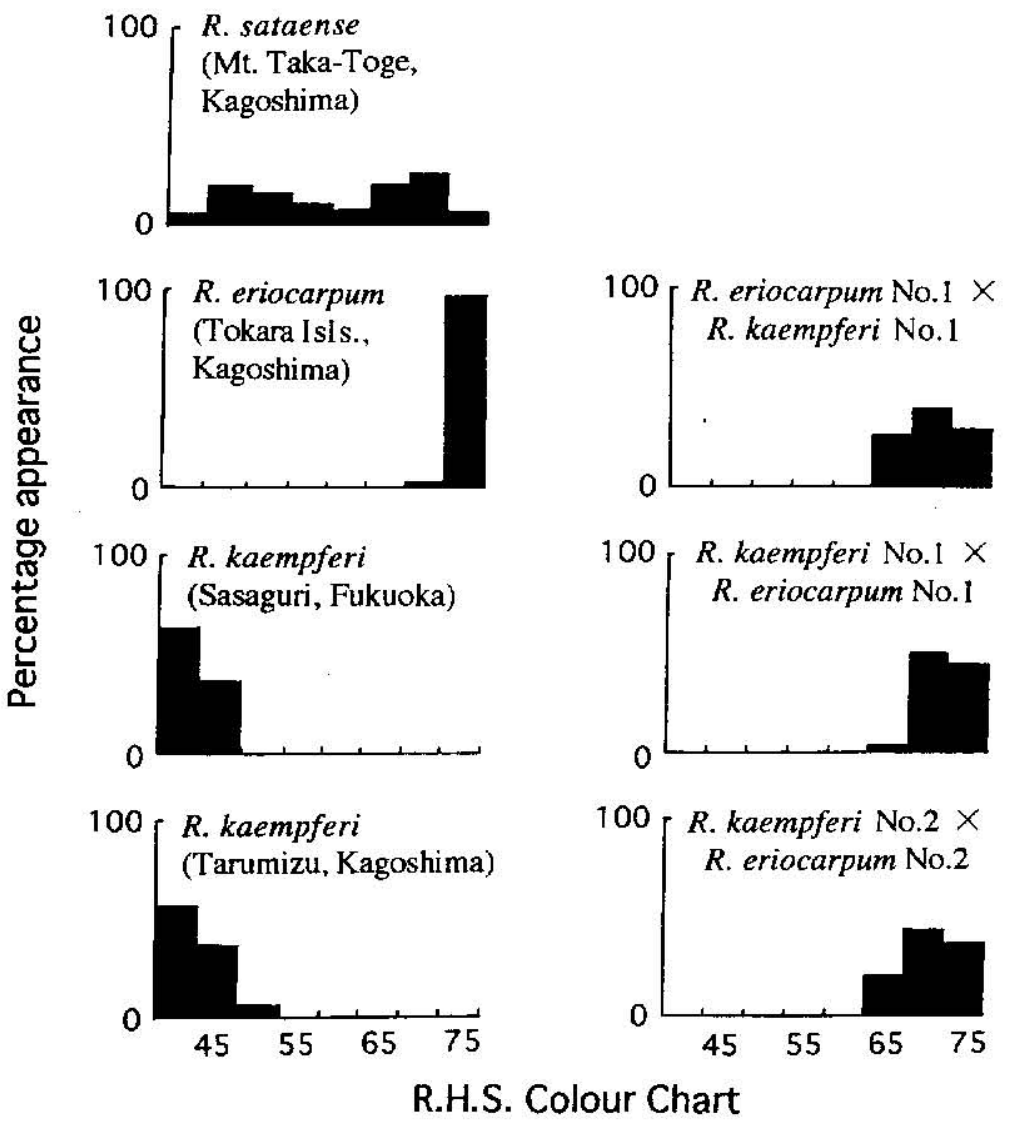

Fig. 2. Frequency of individuals based on the flower colors of wild evergreen azaleas and their interspecific hybrids.

observed in the crossing between $R$. kaempferi No. 1 and $R$ eriocarpum No. 1. However, in the crossing between $R$. kaempferi No. 2 and $R$ eriocarpum No. 2, the percentage of appearance of $\mathrm{F}_{1}$ hybrids that had 5 stamens was about $25 \%$ and almost all other individuals had more than 5 stamens.

Almost all individuals of $R$. eriocarpum contained a high ratio of methylated flavonols in their petals, whereas $R$. kaempferi did a few amount (Fig. 4). The percentages of methylated flavonols in the petals of the $\mathrm{F}$ : hybrids between $R$. kaempfer $i$ No.1 and $R$. eriocarpum No. 1 were different from that of $R$. sataense. The $F_{1}$ hybrids contained 30 to $70 \%$ methylated flavonols, whereas only three out of 125 individuals artalyzed in the populations of $R$. sataense contained the methylated flavonols (Fig. 4). The $\mathrm{F}_{\mathrm{t}}$ hybrids between $R$. kaempferi No. 2 and $R$. eriocarpum No. 2 , however, classified into two groups based on the constitutions of the petal flavonols; one group containing high percentage of methylated flavonols and another one containing low (Fig. 4). 


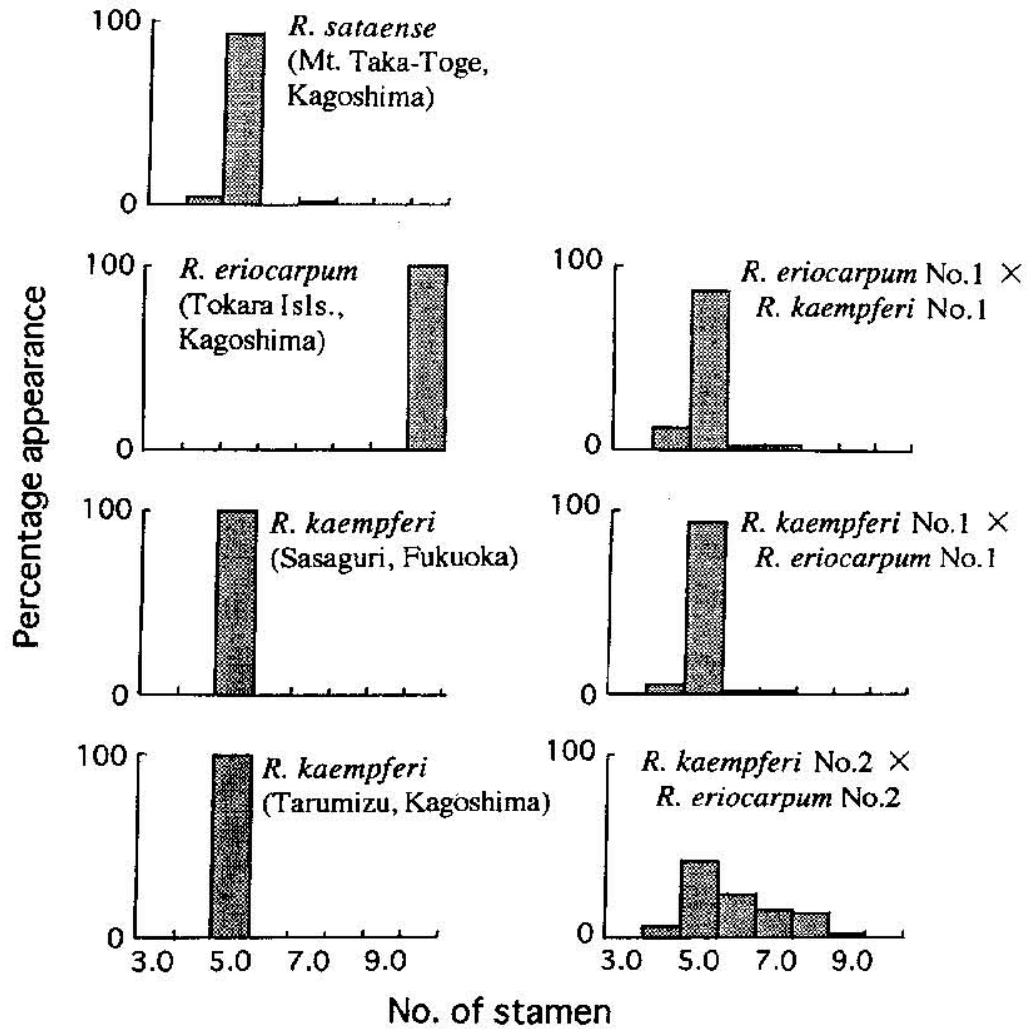

Fig. 3. Frequency of individuals based on number of stamen in wild evergreen azaleas and their interspecific hybrids.

It is possibly suggested from these findings that appearance of the progenies with wide flower color variations and 5 stamens and containing few methylated flavonols in their petals such as $R$. sataense were able to be obtained from the crossing between $R$. eriocarpum and $R$. kaempferi.

On Kirishima and Unzen mountain mass, we investigated the variation of morphological and pigmental characteristics of $R$. kiusianum, $R$. kaempferi and some wild azaleas which have been considered to be their natural hybrids (Sakata et al., 1993; Miyajima et al., 1995). Kunishige and Kobayashi (1980) reported that the populations in Amakusa district, Kyushu island have wide flower color variation and seemed to be derived from the natural crossing between $R$. reticulatum $\mathrm{D}$. Don ex G. Don and $R$. weyrichii Maxim. In addition, the populations which have also flower color variation and thought as the result of the natural crossing between $R$. eriocarpum and $R$. indicum (L.) Sweet were found in Yakushima island. In these cases, the wide flower color variations were observed at the areas where the distribution of purple and red flowered species were overlapped. Therefore, the extremely wide variation of flower colors in $R$. sataense suggests that it is 


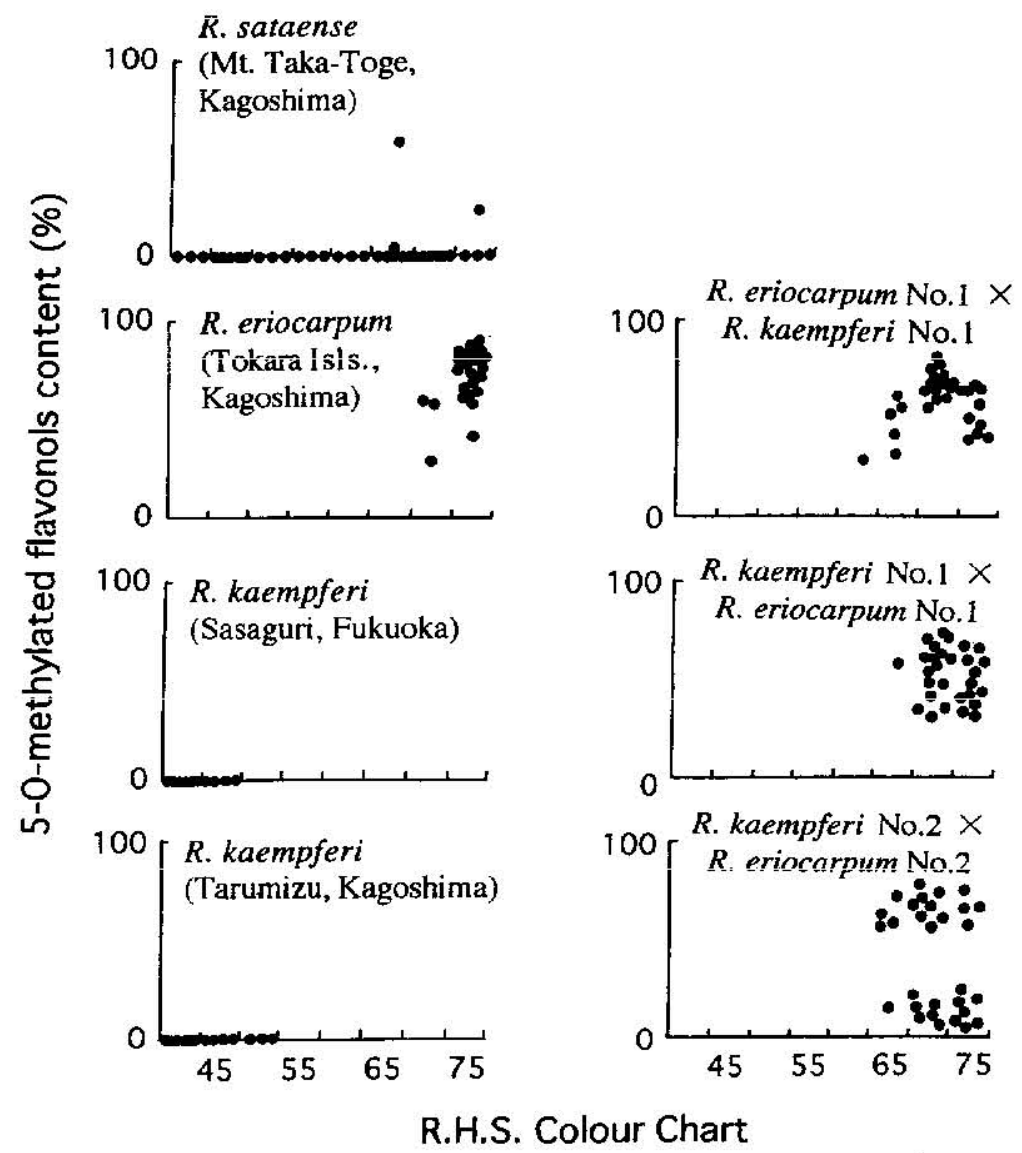

Fig. 4. Distribution of individuals based on the occurrence of 5-O-methylated flavonols in the petals of wild evergreen azaleas and their interspecific hybrids.

an interspecific hybrid between two wild evergreen azaleas that have purple and red flowers.

In previous report (Mivajima et al., 1997), we pointed out that the contribution of $R$. kiusianum to the flower color variation in $R$. sataense seems to be low from the results of the inheritance pattern of flavonol pigments, although this species has purple flowers. And we suggested that the morphological and pigmental characteristics of $R$. sataense should be compared with those of $R$. eriocarpum.

$R$. sataense and $R$. eriocarpum have a similar leal shape (Hatsushima, 1958) and both species distribute closely in southern Kyushu. From these facts, it is suggested that the progenies which have 5 stamens and contained few methylated flavonols in their 
petals such as $R$. sataense were able to become into existence from the crossing between $R$. eriocarpum and $R$. kaempferi.

\section{ACKNOWLEDGMENTS}

The authors wish to thank the Laboratory of Ornamental Horticulture, Faculty of Agriculture, Kagoshima University (present name: Laboratory of Horticultural Products, Faculty of Agriculture, Kagoshima University) for their donation of the rooted cuttings of $R$. eriocarpum collected from Tokara islands.

\section{REFERENCES}

Abe, S. 1969 Sata-tsutsuji to Kirishima-tsutsuji (Rhododendron sataense and R. obtusum). In "Shakunage to Tsutsuji (Rhododendrors and Azaleas)", ed. by Tokyo sansoukai, Seibundoushirkousha, Tokyo, pp. 155-158 (In Japanese)

Hatsushima, S. 1958 On the group of Rhododendron simsit Planch. J. Geobotany., 7(1): $19-22$ (In Japanese)

Kunishige, M. 1978 Establishment cultivars of Kurume azalea. Japanese Joumal of Horticultural Plants, 1: 23-33 (In Japanese)

Kunishige, $\mathrm{M}$. and Y. Kobayashi 1980 Chromatographic identification of Japanese azalea species and their hybrids. In "Contributions toward a classification of Rhododendron", ed. by J. L. Luteyn and M. E. O'Brien, New York Bot. Garden, New York, pp. 277-287

Kunishige, M. and T. Tamura 1961 The natural variation of Rhododendron kaempferi in Mt. Kirishima. Kyushu Agric: Res., 23: 157-158 (In Japanese)

Miyajima, I., S. Ueruolo, Y. Sakala and K. Arisurui 1995 Morpholugical and pigment variations in flowers of Rhododendron kiusianum Makino and R. kaempferi Planch. indigenous to the Inzen mountain mass. J. Japan. Soc. Hort. Sci, 64:393-399 (In Japancse with English summary)

Miyajima, 1., S. Uemoto, Y. Sakata and K. Arisumi 1997 Morphology and flower pigments of wild evergreen azalcas (Rhododendron sataense Nakai) in southern Kyushu. J. Japan. Soc. Hort. Sci., 66: 385391

Sakata, Y., K. Arisumi and I. Miyajima 1993 Variations in some morphological and pigmental characteristics in Rhododendron katmpferi Planch. and $R$. kizsianum Makino and their natural hybrids on Kirishima mountain niass. J. Japan. Soc. Hort. Sci., 61: 925-932 